\title{
las presas de bhakra y nangal
}

S. SARWAL, ingeniero

La presa Bhakra se halla situada en el paraje del mismo nombre, a unos $320 \mathrm{~km}$ al norte de Nueva Delhi (India), al pie de los montes del Himalaya y encajada en un angosto y escarpado paso del río Sutlej, que es el mayor tributario del río Indo.

El proyecto general constituye la construcción de una presa de gravedad, de gran altura, en Bhakra, dos embalses de reserva, un canal de 64 millas de longitud, cuatro centrales generadoras y unos $5.000 \mathrm{~km}$ de canales de distribución de una amplia red de distribución de aguas para riego. A $29 \mathrm{~km}$ de la presa principal se construye la presa de Nangal, de menor altura y capacidad.

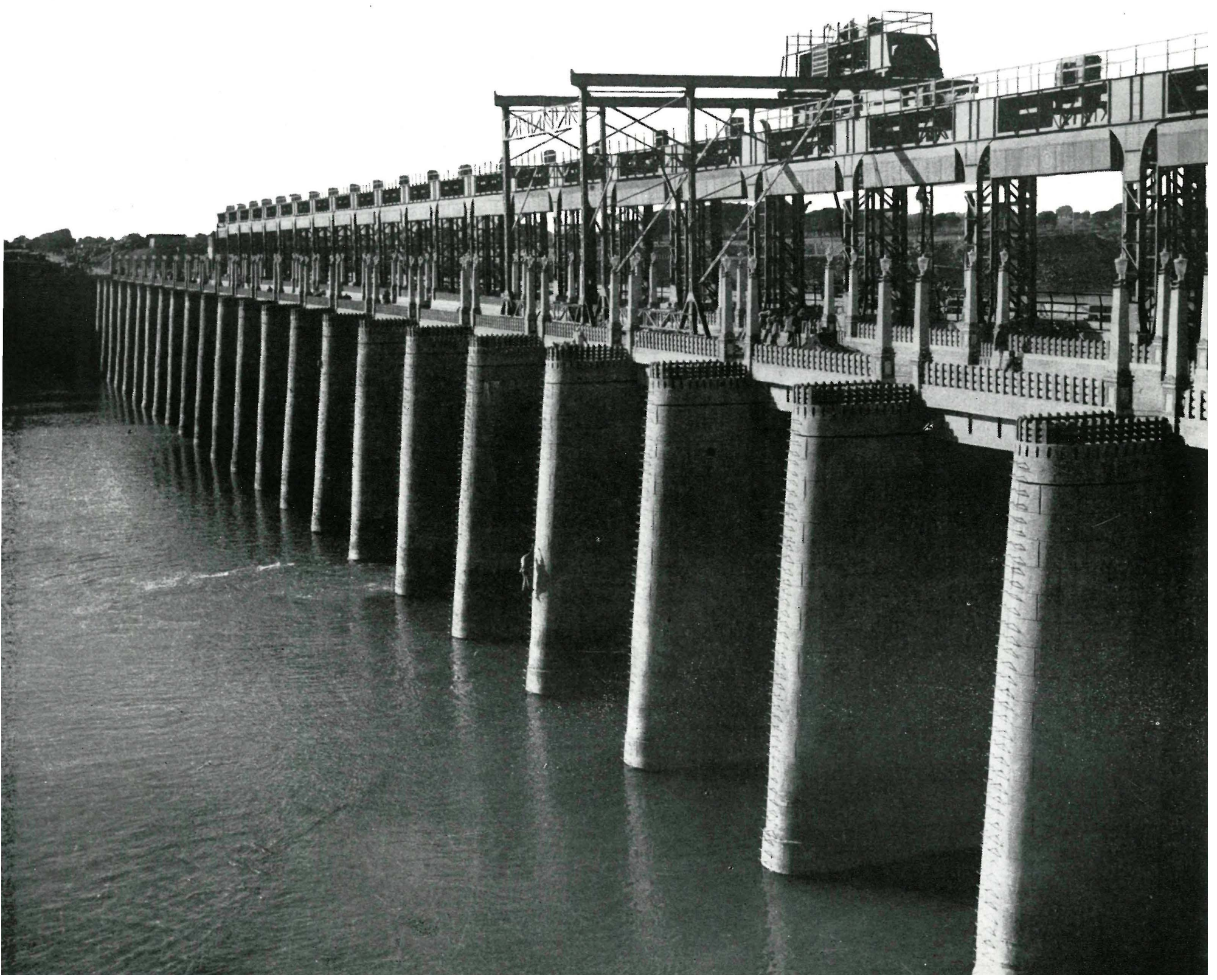




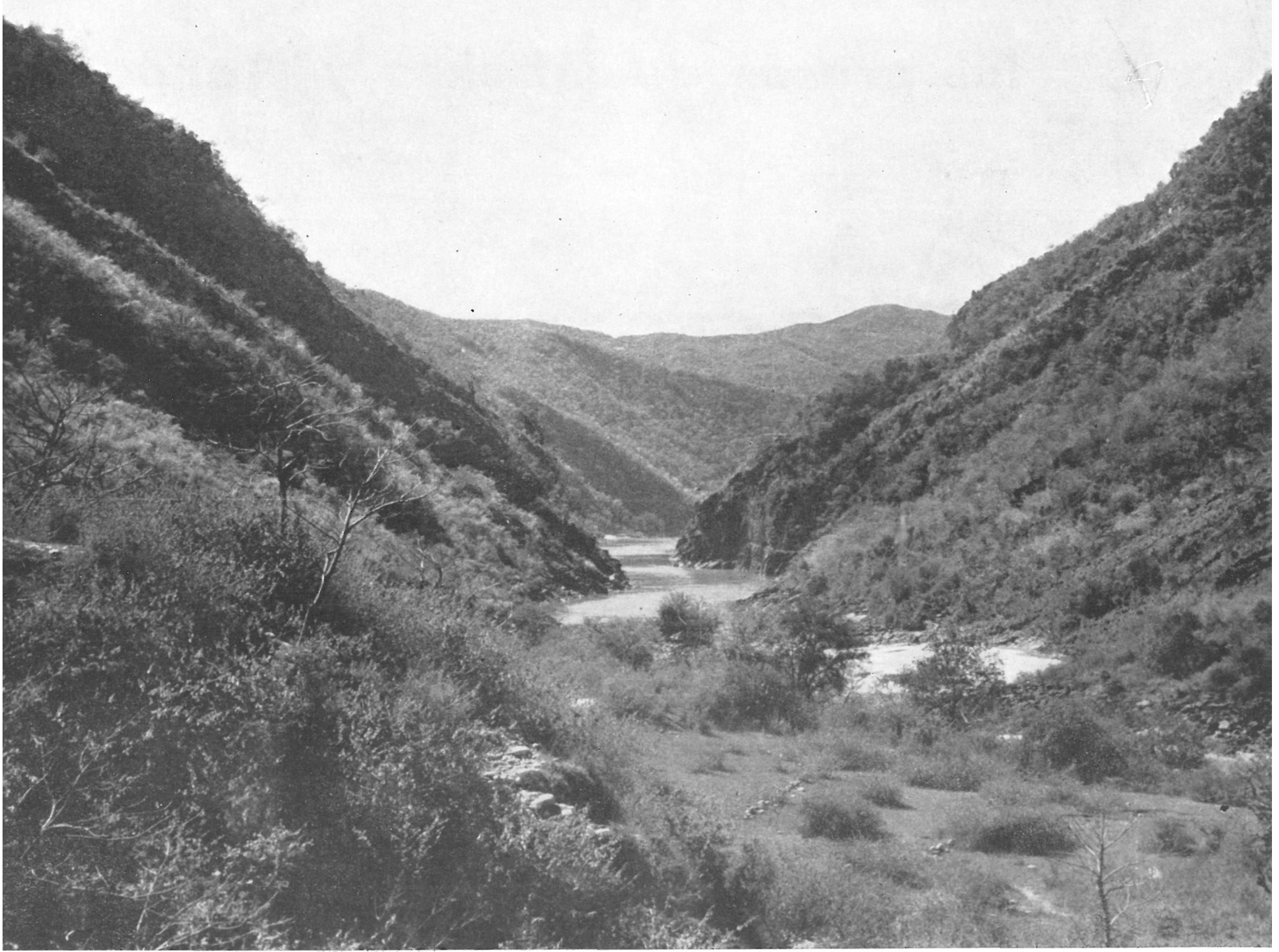

La construcción de esta presa presenta ciertas particularidades de volumen de obra, derivación de aguas y cimientos sobre roca suelta que hacen de este proyecto una empresa que rebasa los límites hasta hoy alcanzados en esta clase de trabajos.

El terreno en el lugar de emplazamiento es movido, variable y formado por vetas de arcilla y bancos de rocas sedimentarias y areniscas.

\section{la presa}

El dique se levanta sobre rocas areniscas en su mayor parte. La presencia de bancos de arcilla ha restringido considerablemente los límites de emplazamiento aceptables para la presa.

La presa es del tipo gravedad, de hormigón en masa y dotada de un gran número de galerías de inspección provistas de ascensores que permiten recorrer toda la presa y cimientos en su parte interior. Estas galerías, de sección rectangular, tienen $1,5 \times 2,00$ metros. Las galerías de cimientos tienen mayor sección para permitir las instalaciones de perforaciones e inyecciones. Como desagüe se han previsto dos galerías de $3,60 \times 5,20 \mathrm{~m}$ de sección.

En estas galerías se han colocado aparatos de medida de temperatura, grietas, tensiones, deformaciones, subpresiones y, en general, para seguir de cerca el comportamiento de la obra.

La presa tiene $225 \mathrm{~m}$ de altura a partir de la roca de cimientos. La longitud total en coronación es de $518 \mathrm{~m}$. La anchura o espesor en la parte superior es de $9 \mathrm{~m}$, y de $198 \mathrm{~m}$ en el pie y en la parte más pronunciada. El volumen de hormigón se eleva a 5,2 millones de metros cúbicos, y para las excavaciones es de unos 4 millones de metros cúbicos.

El aliviadero de superficie se ha proyectado para verter en lámina sobre el cuenco de amortiguamiento donde se absorbe la energía dinámica a la salida del trampolín o salto de esquí. 


\section{embalses de reservo}

De los dos grandes embalses, Govindsagar y Nangal, el primero tiene una capacidad de 9.250 millones de metros cúbicos, y sus aguas se utilizarán en la irrigación a través de una de las mayores redes de canales del mundo.

Para formar este embalse se ha tenido que expropiar un considerable número de viviendas y tierras. El embalse de Nangal, ya en explotación, sirve para compensar las fluctuaciones diarias, y tiene una capacidad de $30.10^{5}$ metros cúbicos.

\section{cimienfos}

El apoyo de esta presa se ha realizado sobre un terreno de escasa capacidad de sustentación, lo que ha dado lugar a serias complicaciones. La excavación en roca estratificada se ha realizado siguiendo un cuidadoso rigor y tratamiento en la zona de apoyo, ya que la presa debía alcanzar una gran altura. Los sondeos y galerias de reconocimiento han sido muchos y muy variados para poder conocer el estado del terreno con suficiente seguridad.

Se empezó por preparar los cimientos en las laderas y márgenes escarpadas de la gran garganta que forma el valle del río, para lo cual hubo que amarrar al personal con cuerdas con objeto de poder trabajar dentro de los límites de una seguridad personal aceptable. Las vetas de arcilla blanda se lavaron con agua inyectada a presión. En estos trabajos se utilizó material auxiliar moderno, palas y camiones de gran capacidad.

El rendimiento máximo en la excavación fué de unos 9.000 metros cúbicos por turno de 8 horas. Se dispuso de un orden y cuidado especial para la excavación al llegar a los $60 \mathrm{~m}$ de profundidad bajo el fondo del rio.

\section{preparación del hormigón}

El transporte de áridos entre las canteras y la central de hormigón se realizó por medio de una cinta sin fin. La capacidad de esta cinta, que cruza el río, es del orden de 800 toneladas por hora. El recorrido se compone de varios tramos, y en caso de avería en uno de ellos se para la explotación automáticamente.

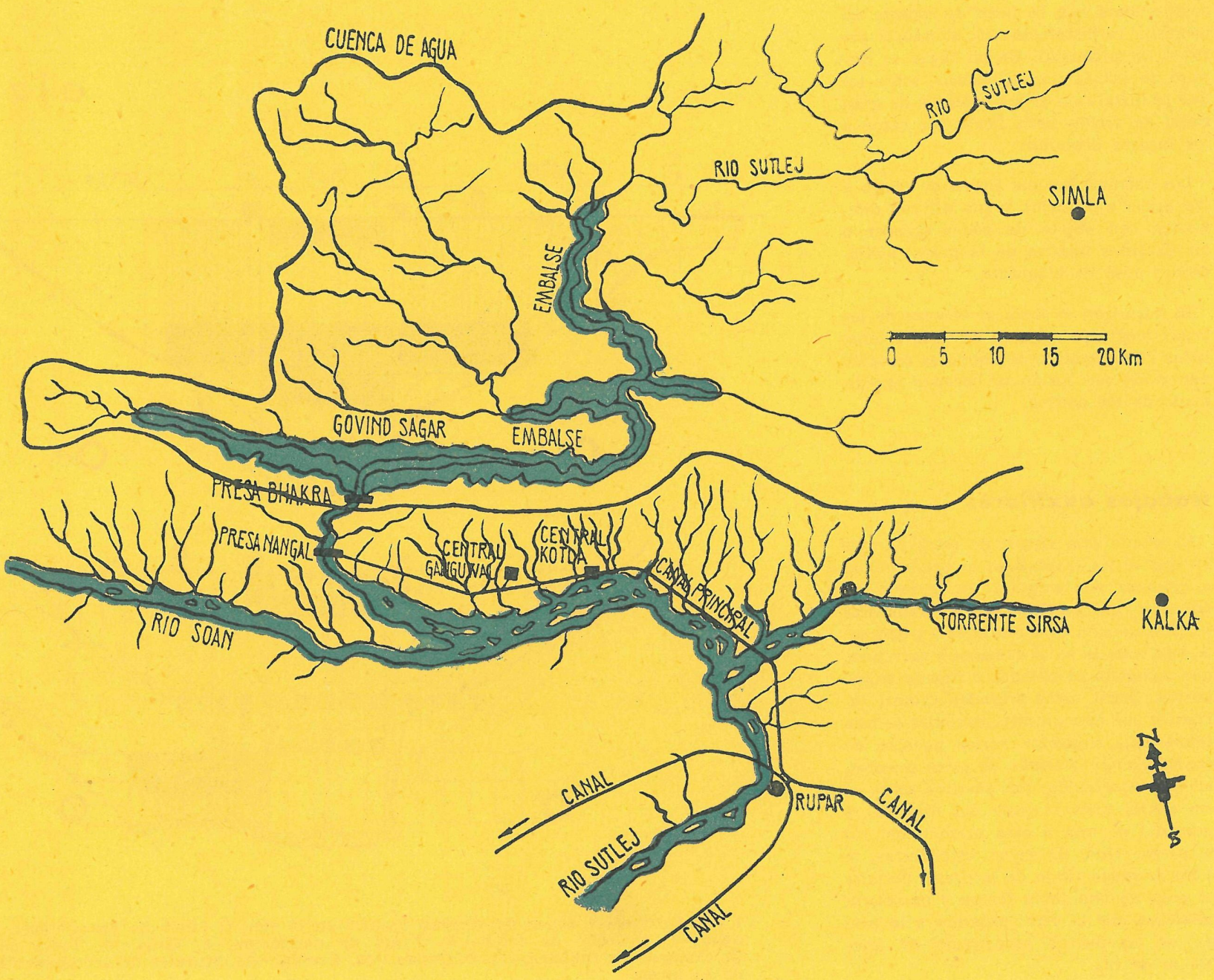


Debido a la falta de plataformas amplias, pues las laderas son muy escarpadas, el machaqueo y preparación de finos fué muy laborioso.

Para reducir el calor de hidratación en el fraguado se fijó una temperatura de $18^{\circ} \mathrm{C}$ para la colocación del hormigón y de $6^{\circ} \mathrm{C}$ para los áridos. La gran diferencia de temperatura entre áridos y hormigón es para tener en cuenta el calentamiento de los áridos durante el transporte y en el período de las estaciones de calor.

Las instalaciones de frío sirven para el enfriamiento del agua y áridos a través de corrientes de agua que pasan por los áridos siguiendo ciclos de refrigeración. Para mantener una temperatura inofensiva para la retracción y agrietamiento, los bloques que se van hormigonando en la presa se enfrían con serpentines en los que circula agua fría.

\section{colocación del \\ hormigón en obra}

El hormigonado de una presa de este volumen y altura crea serios problemas.

Como la garganta en que se ha situado la presa es muy escarpada y el espesor en la base es de unos $400 \mathrm{~m}$, se comprenderá que la falta de espacio no aconseja la instalación de blondines para el hormigonado. En su lugar se dispuso de entramados metálicos, sobre los que se instalaron grúas potentes de gran radio de acción para llevar los cazos a los lugares deseados.

Los entramados que sirven de apoyo a las grúas son varios y sus alturas diferentes, con objeto de poder acceder a los distintos lugares de la presa, aliviadero y casa de mácuinas.

El hormigón se lleva al alcance de las gruas mediante vagones de unas 8 toneladas de capacidad, de donde es recogido por grúas que tienen un alcance aproximado de 100 metros.

\section{trabajos auxilliares}

El estado casi virgen de estos parajes en que se ha emplazado la presa obligó a empezar por estudiar un trazado ferroviario, que serviría para el transporte y aproximación de materiales y personal. A este trazado se le suma una carretera, que completa el sistema o red de transportes. Como estos trazados cruzan torrentes que dan grandes caudales se han tenido que construir varios puentes de consideración. Además de estos puentes, se han construido dos puentes sobre el río Sutlej para el paso del material 8 personal de una a otra margen del río o presa. Una de estas estructuras, a $1.600 \mathrm{~m}$ aguas abajo de la presa, permite el paso de una línea férrea y carretera. mientras que la otra, próxima a la presa, es un puente suspendido de unos $240 \mathrm{~m}$ de luz.

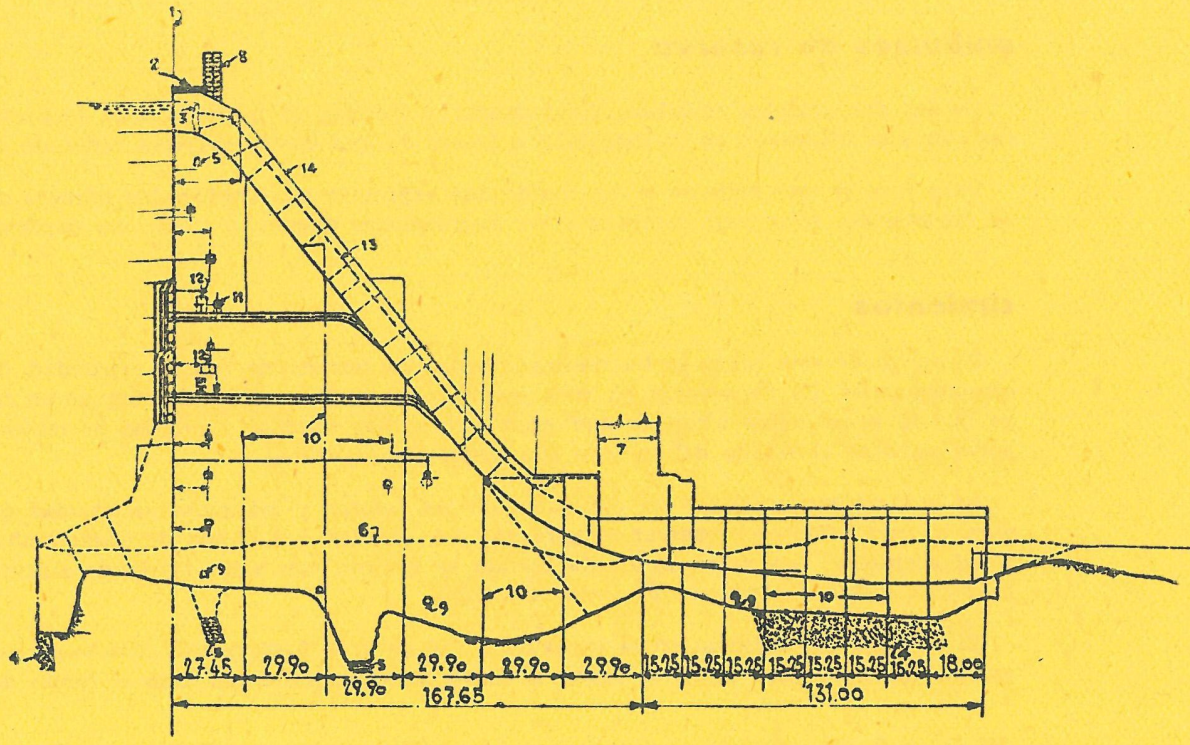

1. Eje de la presa.-2. Carretera.-3. Compuerta radial.-4. Banco de arcilla.-5. Galería en cimientos. -6. Línea del terreno natural.-7. Central.-8. Torre de elevación.-9. Galería de 13. Vertedero del aliviadero - 14 . Aliviadero.

sección
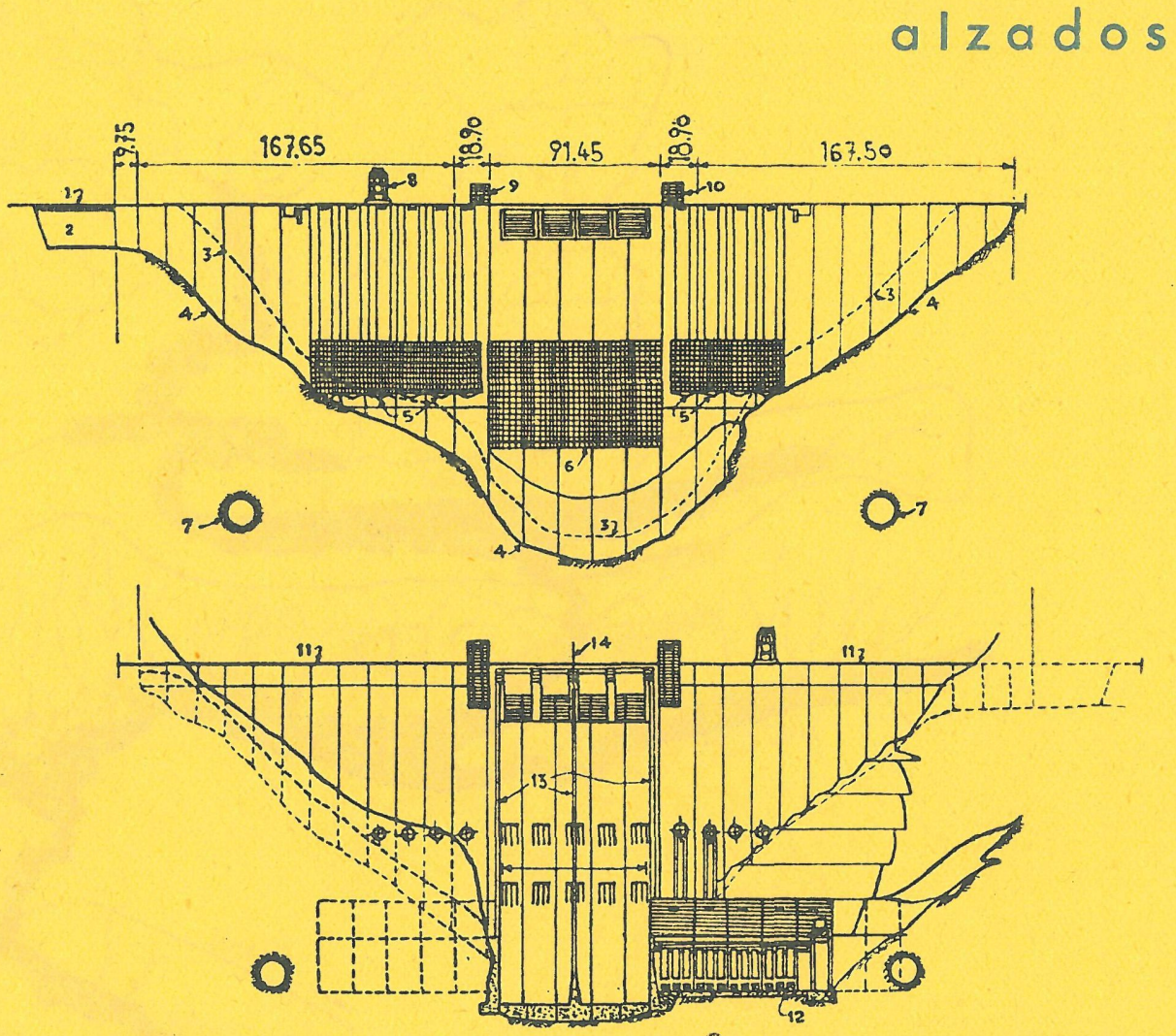

1 y 2. Estribo.-3. Linea del terreno natural en el eje. -4. Linea de excavaciones. -5 . Toma de agua.-6. Desagùe de fondo.-7. Túnel de derivación.-8. Grúa.-9. Torre de elevación.10. Compuertas radiales.-11. Carretera.-12. Central.-13. Muretes de acompañamiento.-14. Eje de la presa. 

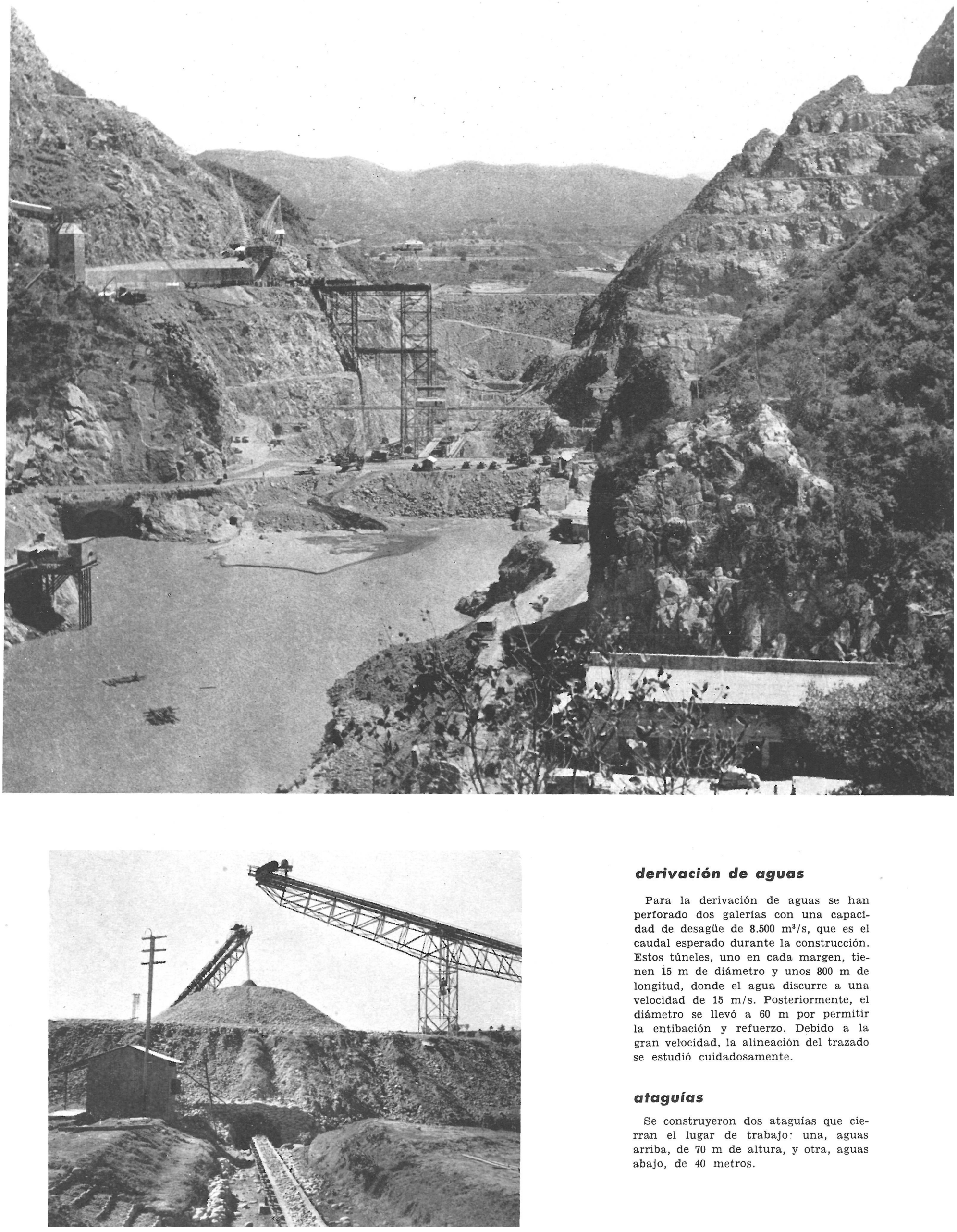

\section{derivación de aguas}

Para la derivación de aguas se han perforado dos galerías con una capacidad de desagüe de $8.500 \mathrm{~m}^{3} / \mathrm{s}$, que es el caudal esperado durante la construcción. Estos túneles, uno en cada margen, tienen $15 \mathrm{~m}$ de diámetro y unos $800 \mathrm{~m}$ de longitud, donde el agua discurre a una velocidad de $15 \mathrm{~m} / \mathrm{s}$. Posteriormente, el diámetro se llevó a $60 \mathrm{~m}$ por permitir la entibación y refuerzo. Debido a la gran velocidad, la alineación del trazado se estudió cuidadosamente.

\section{ataguías}

Se construyeron dos ataguías que cierran el lugar de trabajo: una, aguas arriba, de $70 \mathrm{~m}$ de altura, y otra, aguas abajo, de 40 metros. 

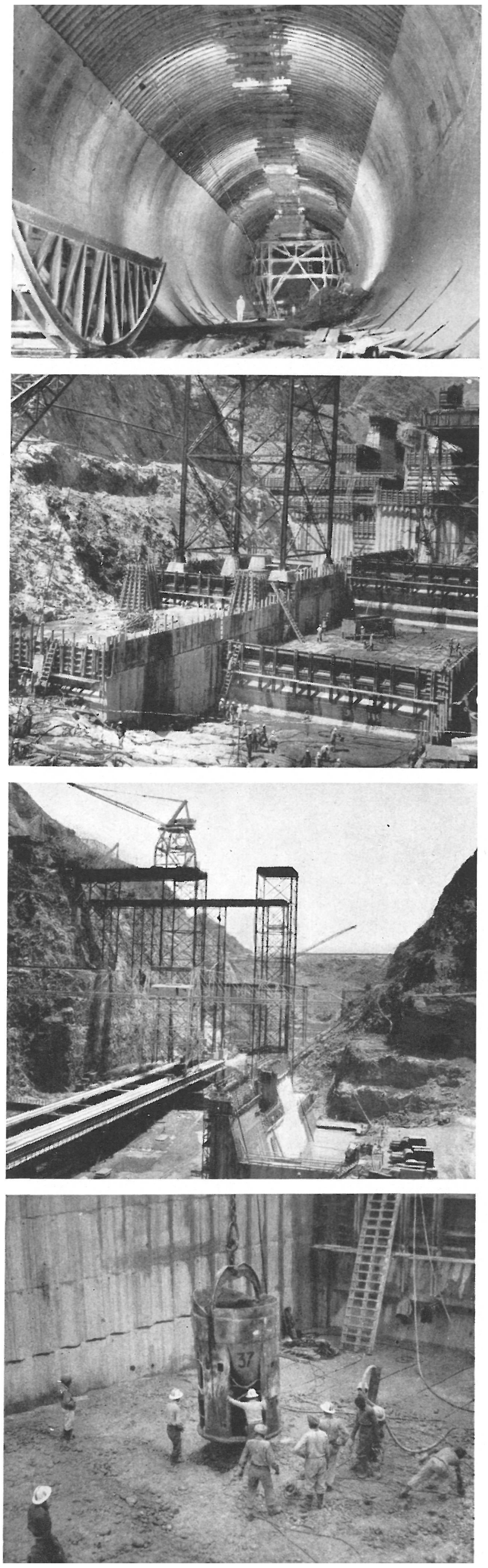

Aparte los túneles de derivación, se han construído varios de ellos con distintos motivos: para ferrocarril, carretera, cinta transportadora, tuberías forzadas, galerias de acceso y de drenaje.

\section{instalaciones}

Para parar las dificultades locales y sacar el mayor partido posible de las instalaciones, éstas se han situado entre la presa principal de Bhakra y la de Nangal, lo que ha permitido ciertas ventajas y mejoras económicas en la ejecución. Entre las instalaciones se cuentan los talleres mecánicos, generación de frío y talleres electro-mecánicos.
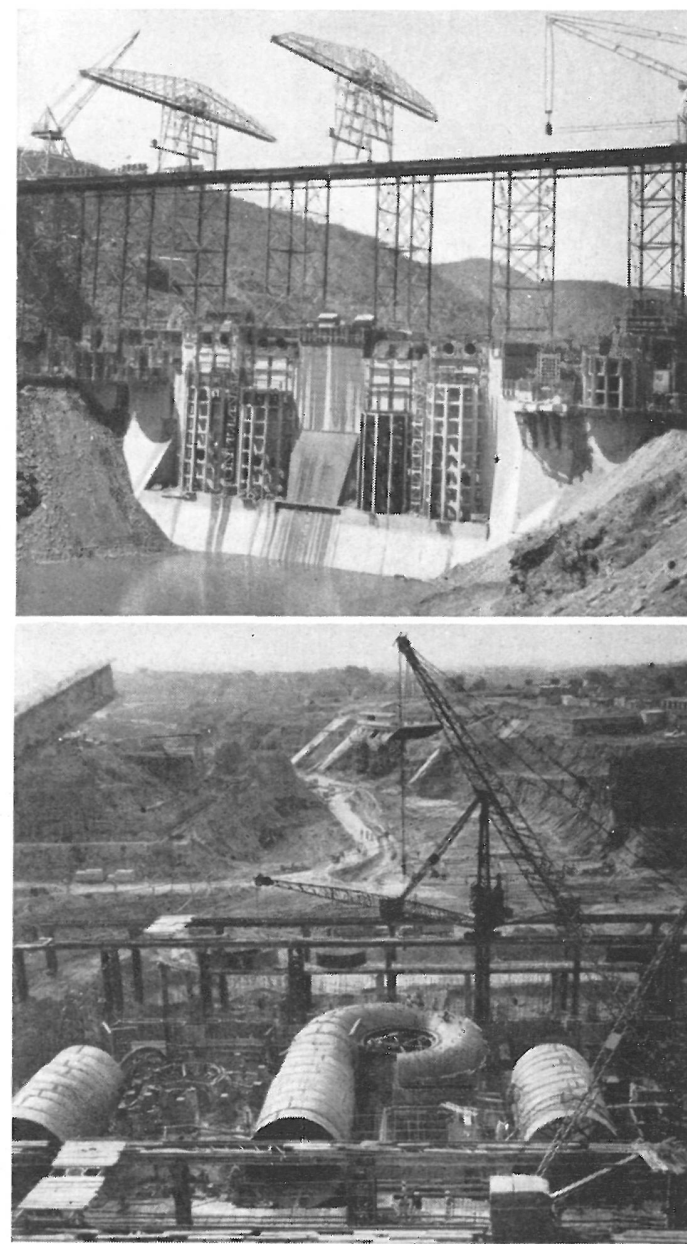

\section{acantonamiento}

Para alojar al personal se han construído unas 4.000 viviendas de distintos tipos. Todas estas construcciones se han dotado de confort corriente, agua y electricidad.

Toma de aguas.

Virolas para las turbinas de la central Ganguwal. 

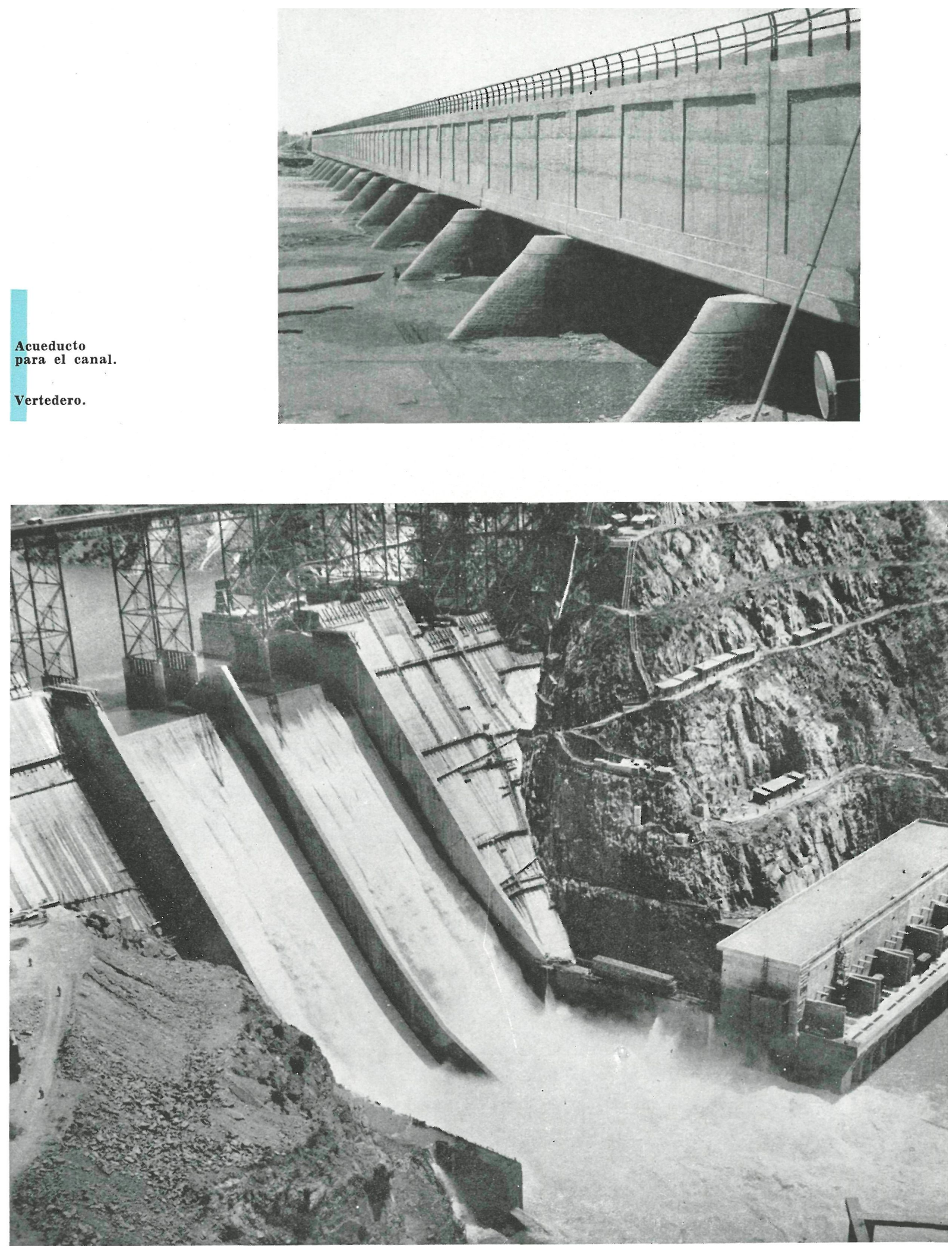

\section{la presa Nangal}

La presa, situada unos $12 \mathrm{~km}$ aguas abajo de la de Bhakra, está constituída por una estructura de hormigón de $29 \mathrm{~m}$ de altura y unos $300 \mathrm{~m}$ de longitud. El objeto principal de esta presa es el de la irrigación. No obstante, se han construído dos centrales generadoras de energía eléctrica, de pequeño salto, y se piensa construir una tercera en el futuro. Esta presa tiene por función derivada la de regular caudales en el canal principal de suministro de agua.

El canal principal toma sus aguas entre las dos presas, y antes de entrar en la planicie ha tenido que cruzar algunos torrentes y colinas de relativa altura, dando con ello lugar a una serie importante de obras de fábrica, viaductos y sifones. 

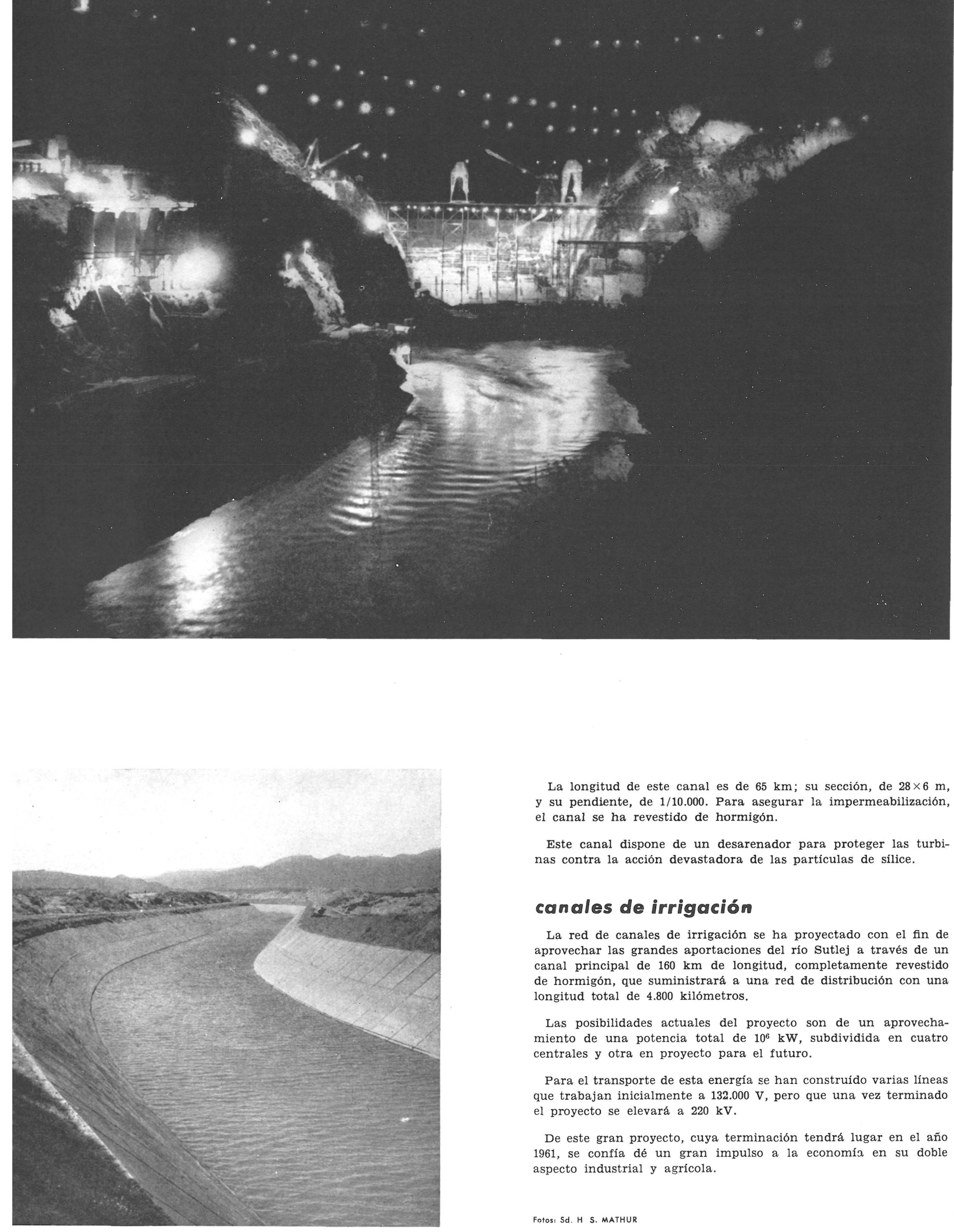

La longitud de este canal es de $65 \mathrm{~km}$; su sección, de $28 \times 6 \mathrm{~m}$, y su pendiente, de $1 / 10.000$. Para asegurar la impermeabilización, el canal se ha revestido de hormigón.

Este canal dispone de un desarenador para proteger las turbinas contra la acción devastadora de las partículas de sílice.

\section{canales de irrigación}

La red de canales de irrigación se ha proyectado con el fin de aprovechar las grandes aportaciones del río Sutlej a través de un canal principal de $160 \mathrm{~km}$ de longitud, completamente revestido de hormigón, que suministrará a una red de distribución con una longitud total de 4.800 kilómetros.

Las posibilidades actuales del proyecto son de un aprovechamiento de una potencia total de $10^{6} \mathrm{~kW}$, subdividida en cuatro centrales y otra en proyecto para el futuro.

Para el transporte de esta energía se han construído varias líneas que trabajan inicialmente a $132.000 \mathrm{~V}$, pero que una vez terminado el proyecto se elevará a $220 \mathrm{kV}$.

De este gran proyecto, cuya terminación tendrá lugar en el año 1961, se confía dé un gran impulso a la economía en su doble aspecto industrial y agrícola. 